\title{
Imaging of glial tumor recurrence using $\left[{ }^{68} \mathrm{Ga}\right] \mathrm{Ga}$-PSMA- $11 \mathrm{PET} / \mathrm{CT}$
}

\author{
Jolanta Kunikowska \\ Medical University of Warsaw \\ Rafał Czepczyński ( $\square$ czepczynski@ump.edu.pl) \\ Poznan University of Medical Sciences \\ Dariusz Pawlak \\ National Centre for Nuclear Research \\ Henryk Koziara \\ Maria Skłodowska-Curie Memorial Cancer Center and Institute of Oncology \\ Kacper Petka \\ Medical University of Warsaw \\ Leszek Królicki \\ Medical University of Warsaw
}

\section{Research Article}

Keywords: PSMA, glioblastoma, GBM, glioma, oligodendroglioma, [68Ga]Ga-PSMA-11

Posted Date: August 30th, 2021

DOI: https://doi.org/10.21203/rs.3.rs-848828/v1

License: (c) (i) This work is licensed under a Creative Commons Attribution 4.0 International License. Read Full License 


\section{Abstract}

Background and Purpose

Limited data is available on the possible use of $\left[{ }^{68} \mathrm{Ga}\right] \mathrm{Ga}$-PSMA-11 PET/CT for the diagnosis of glioma recurrence. The aim of this paper was to assess the use of $\left[{ }^{68} \mathrm{Ga}\right] \mathrm{Ga}-\mathrm{PSMA}-11$ PET/CT for the detection of recurrence in different glial tumors.

Materials and Methods

34 patients (pts.) aged $44.5 \pm 10.3$ years with suspicion of recurrence of histologically confirmed glioma grade III (6 pts.) and grade IV (28 pts.) were included in the study. All patients underwent contrast-enhanced MR and $\left[{ }^{68} \mathrm{Ga}\right] \mathrm{Ga}-$ PSMA-11 PET/CT.

Results

No radiopharmaceutical-related adverse events were noted. PET/CT was positive in all the areas suspected for recurrence at MR in all the patients. The recurrence was confirmed by histopathological examinations or follow-up imaging in all cases. The images showed a very low background activity of the normal brain. Median maximal standard uptake value (SUVmax) of the tumors was 6.5 (range: 0.9-15.6) and mean standard uptake value (SUVmean) was 3.5 (range: 0.9-7.5). Target-to-background (TBR) ratios varied between 15 and 1400 with a median of 152. Target-to-liver background ratios (TLR) ranged from 0.2 to 2.6, the median TLR was 1.3. No significant difference of the measured parameters was found between the subgroups according to the glioma grade.

Conclusion

$\left[{ }^{68} \mathrm{Ga}\right] \mathrm{Ga}-\mathrm{PSMA}-11 \mathrm{PET} / \mathrm{CT}$ shows excellent results in the diagnosis of glioma recurrence of various grades. Due to the very low background activity, this method provides high-quality images and allows for the detection of welldefined recurrence lesions.

\section{Introduction}

Primary glial tumors are the most prevalent types of brain tumors in adults, with heterogenous histology. The World Health Organization Classification of Tumors of the Central Nervous System (WHO 2016) is based not only on histopathological features, but also on the expression of specific molecular biomarkers [1]. According to this classification, different histopathological subtypes, of which astrocytoma (60-70\%), oligodendroglioma (10-30\%) and ependymoma $(<10 \%)$ are the most common, are stratified into four prognostic grades.

Therapy involves surgery followed by radiation therapy, usually in combination with chemotherapy. As the prognosis in high-grade gliomas is generally poor and recurrences occur frequently, a reliable diagnostic tool to detect early relapse is necessary. Usually, at first contrast-enhanced magnetic resonance imaging (MR) is used for the detection of recurrence [2]. The main MR limitation, however, is its low specificity in the differentiation of residual disease and postoperative inflammation, radiation necrosis or pseudoprogression [3, 4]. In order to improve diagnostic accuracy, $\mathrm{PET} / \mathrm{CT}$ or PET/MR using different radiopharmaceuticals is employed to verify the possibility of recurrence. The most common and available PET radiotracer, FDG, presents a major limitation posed by the physiologically high glucose consumption in the grey matter as well as relatively low FDG accumulation in the glioma tissue [5]. 
Amino acids PET tracers, such as ${ }^{18} \mathrm{~F}$-fluoroethyltyrosine, ${ }^{18} \mathrm{~F}$-fluorotyrosine and ${ }^{11} \mathrm{C}$-methionine are increasingly used in the diagnosis of gliomas, due to the high uptake in the tumor and low uptake in the normal brain [6]. The availability of these tracers is limited due to the high cost and restricted availability. Labeling with gallium-68 $\left({ }^{68} \mathrm{Ga}\right)$ can, to a certain degree, avoid some of these technical obstacles due to its generator-based production.

Prostate specific membrane antigen (PSMA) is known to be overexpressed in prostate cancer cells. Immunohistochemical examination revealed the expression of PSMA not only in the prostate cancer but also in other tumors, including glial tumors, though with various intensity $[7,8]$. For several years, $\left[{ }^{68} \mathrm{Ga}\right] \mathrm{Ga}-\mathrm{PSMA}-11$ has been successfully used as a PET radiopharmaceutical for the imaging of prostate cancer, for both, staging and detection of recurrence [9]. In the case of glial tumors, experience with [ ${ }^{68} \mathrm{Ga}$ Ga-PSMA-11 PET/CT is rather limited. Only a few studies have focused on the use of $\left[{ }^{68} \mathrm{Ga}\right] \mathrm{Ga}$-PSMA-11 PET/CT in patients with glioblastoma multiforme and (even less) in other types of glial tumors [10-16].

The aim of this paper was to comprehensively analyze the use of $\left[{ }^{68} \mathrm{Ga}\right] \mathrm{Ga}-\mathrm{PSMA}-11 \mathrm{PET} / \mathrm{CT}$ for the detection of recurrence in different glial tumors.

\section{Materials And Methods}

This was a single-institution study performed in accordance with the Declaration of Helsinki. It was approved by the Ethical Committee of Medical University of Warsaw (KB/235/2016 and KB/2/A/2018). Written informed consent was obtained from all patients.

\section{Patients}

Patients with a suspicion of recurrence of glial tumors based on MR evaluation were qualified to the study. The study group consisted of 34 patients (22 male, 12 female pts.) aged $44.5 \pm 10.3$ years. The histopathological diagnosis was obtained before treatment initiation. 6 patients were diagnosed of grade III glioma and 28 patients of grade IV (glioblastoma). The detailed WHO 2016 classification and patient's treatment history of each patient is listed in Table 1. 
Table 1

Detailed patients' data.

\begin{tabular}{|c|c|c|c|c|c|c|c|c|}
\hline No & Gender & Age & $\begin{array}{l}\text { Grade and WHO } \\
2016 \text { type }\end{array}$ & $\begin{array}{l}\text { Localisation } \\
\text { [lobe] }\end{array}$ & Treatment & $\begin{array}{l}\text { Other } \\
\text { treatment }\end{array}$ & $\begin{array}{l}\text { Time to } \\
\text { recurrence } \\
\text { [months] }\end{array}$ & $\begin{array}{l}\text { Recurrent } \\
\text { tumor } \\
\text { volume } \\
{\left[\mathrm{cm}^{3}\right]}\end{array}$ \\
\hline 1 & $M$ & 35 & $\begin{array}{l}\text { III } \\
\text { Anaplastic } \\
\text { astrocytoma NOS }\end{array}$ & $\mathrm{R}$ frontal & $S$ & & 3.5 & 23.8 \\
\hline 2 & $M$ & 39 & $\begin{array}{l}\text { III } \\
\text { Anaplastic } \\
\text { astrocytoma IDH } \\
\text { wildtype }\end{array}$ & $\begin{array}{l}\text { R parieto- } \\
\text { occipital }\end{array}$ & $\begin{array}{l}\text { S, RTx, } \\
\text { CHT }\end{array}$ & $\begin{array}{l}{\left[{ }^{213} \mathrm{Bi}\right] \mathrm{Bi}-} \\
\text { DOTA-SP }\end{array}$ & 37.3 & 28.4 \\
\hline 3 & $F$ & 49 & $\begin{array}{l}\text { III } \\
\text { Anaplastic } \\
\text { astrocytoma IDH } \\
\text { wildtype }\end{array}$ & $\begin{array}{l}\mathrm{R} \\
\text { temporalo- } \\
\text { occipital }\end{array}$ & $\begin{array}{l}\text { S, RTX, } \\
\text { CHT }\end{array}$ & & 108.4 & 108.0 \\
\hline 4 & $\mathrm{~F}$ & 43 & $\begin{array}{l}\text { III } \\
\text { Oligodendroglioma } \\
\text { IDH mutant }\end{array}$ & $\begin{array}{l}\text { R frontal } \\
\text { multifocal }\end{array}$ & S, RTx & Irinotecan & 87.1 & 49.7 \\
\hline 5 & $\mathrm{~K}$ & 27 & $\begin{array}{l}\text { III } \\
\text { Anaplastic } \\
\text { astrocytoma NOS }\end{array}$ & multifocal & $\begin{array}{l}\text { S, RTX, } \\
\text { CHT }\end{array}$ & $\begin{array}{l}{\left[{ }^{225} A c\right] A C-} \\
\text { DOTA-SP } \\
\text { TMZ }\end{array}$ & 59.0 & 73.3 \\
\hline 6 & $M$ & 50 & $\begin{array}{l}\text { III } \\
\text { Secondary } \\
\text { Anaplastic } \\
\text { oligodendroglioma } \\
\text { NOS }\end{array}$ & $\begin{array}{l}\text { L frontal } \\
\text { multifocal }\end{array}$ & S,RTx,CHT & Irinotecan & 200.0 & 18.5 \\
\hline 7 & $M$ & 69 & $\begin{array}{l}\text { IV } \\
\text { Glioblastoma IDH } \\
\text { wildtype }\end{array}$ & R parietal & S, Rtx & TMZ & 3.9 & 22.9 \\
\hline 8 & $M$ & 54 & $\begin{array}{l}\text { IV } \\
\text { Glioblastoma NOS }\end{array}$ & $\mathrm{R}$ frontal & S, RTx & TMZ & 28.2 & 32.6 \\
\hline 9 & $M$ & 45 & $\begin{array}{l}\text { IV } \\
\text { Glioblastoma NOS }\end{array}$ & $\begin{array}{l}\mathrm{L} \text { deep } \\
\text { structures }\end{array}$ & S, RTx & TMZ & 11.0 & 42.3 \\
\hline 10 & $\mathrm{~F}$ & 44 & $\begin{array}{l}\text { IV } \\
\text { Secondary } \\
\text { Glioblastoma IDH } \\
\text { wildtype }\end{array}$ & $L$ temporal & $\begin{array}{l}\text { S, RTX, } \\
\text { CHT }\end{array}$ & $\begin{array}{l}{\left[{ }^{213} \mathrm{Bi}\right] \mathrm{Bi}-} \\
\text { DOTA-SP }\end{array}$ & 184.1 & 22.1 \\
\hline
\end{tabular}

R- right; L- left; S- surgery; RTx- radiotherapy; CHT- chemotherapy, TMZ- Temozolamide 


\begin{tabular}{|c|c|c|c|c|c|c|c|c|}
\hline No & Gender & Age & $\begin{array}{l}\text { Grade and WHO } \\
2016 \text { type }\end{array}$ & $\begin{array}{l}\text { Localisation } \\
\text { [lobe] }\end{array}$ & Treatment & $\begin{array}{l}\text { Other } \\
\text { treatment }\end{array}$ & $\begin{array}{l}\text { Time to } \\
\text { recurrence } \\
\text { [months] }\end{array}$ & $\begin{array}{l}\text { Recurrent } \\
\text { tumor } \\
\text { volume } \\
{\left[\mathrm{cm}^{3}\right]}\end{array}$ \\
\hline 11 & M & 33 & $\begin{array}{l}\text { IV } \\
\text { Glioblastoma IDH } \\
\text { mutant }\end{array}$ & $\begin{array}{l}\mathrm{R} \text { fronto- } \\
\text { parietal }\end{array}$ & $\begin{array}{l}\text { S, RTX, } \\
\text { CHT }\end{array}$ & & 15.9 & 25.3 \\
\hline 12 & $\mathrm{~F}$ & 51 & $\begin{array}{l}\text { IV } \\
\text { Glioblastoma IDH } \\
\text { wildtype - giant cell }\end{array}$ & $\begin{array}{l}\mathrm{R} \text { fronto- } \\
\text { parietal }\end{array}$ & $\begin{array}{l}\text { S, RTX, } \\
\text { CHT }\end{array}$ & $\begin{array}{l}{\left[{ }^{213} \mathrm{Bi}\right] \mathrm{Bi}-} \\
\text { DOTA-SP }\end{array}$ & 46.7 & 107.2 \\
\hline 13 & $M$ & 16 & $\begin{array}{l}\text { IV } \\
\text { Glioblastoma IDH } \\
\text { mutant }\end{array}$ & $\begin{array}{l}\mathrm{L} \text { fronto- } \\
\text { parietal }\end{array}$ & $\begin{array}{l}\text { S, RTX, } \\
\text { CHT }\end{array}$ & & 3.2 & 244.2 \\
\hline 14 & $M$ & 37 & $\begin{array}{l}\text { IV } \\
\text { Secondary } \\
\text { Glioblastoma NOS }\end{array}$ & $\mathrm{R}$ frontal & $\begin{array}{l}\text { S, RTX, } \\
\text { CHT }\end{array}$ & $\mathrm{TMZ}$ & 111.5 & 70.6 \\
\hline 15 & $\mathrm{~F}$ & 25 & $\begin{array}{l}\text { IV } \\
\text { Secondary } \\
\text { Glioblastoma IDH } \\
\text { mutant }\end{array}$ & $L$ insular & $\begin{array}{l}\text { S, RTx, } \\
\text { CHT }\end{array}$ & $\begin{array}{l}{\left[{ }^{225} \text { Ac]AC- }\right.} \\
\text { DOTAGA- } \\
\text { SP }\end{array}$ & 64.6 & 4.7 \\
\hline 16 & $M$ & 47 & $\begin{array}{l}\text { IV } \\
\text { Glioblastoma NOS }\end{array}$ & $\begin{array}{l}\text { L parieto- } \\
\text { occipital }\end{array}$ & $\begin{array}{l}\text { S, RTX, } \\
\text { CHT }\end{array}$ & & 6.3 & 120.2 \\
\hline 17 & $M$ & 43 & $\begin{array}{l}\text { IV } \\
\text { Secondary } \\
\text { Glioblastoma NOS }\end{array}$ & L parietal & S, RTx & TMZ & 49.1 & 6.3 \\
\hline 18 & $\mathrm{~F}$ & 47 & $\begin{array}{l}\text { IV } \\
\text { Glioblastoma NOS }\end{array}$ & $\mathrm{R}$ parietal & $\begin{array}{l}\text { S, RTX, } \\
\text { CHT }\end{array}$ & & 19.4 & 113.5 \\
\hline 19 & M & 42 & $\begin{array}{l}\text { IV } \\
\text { Glioblastoma IDH } \\
\text { mutant }\end{array}$ & $\begin{array}{l}\mathrm{R} \text { fronto- } \\
\text { parietal }\end{array}$ & $\begin{array}{l}\text { S, RTX, } \\
\text { CHT }\end{array}$ & TMZ & 27.2 & 142.2 \\
\hline 20 & $\mathrm{~F}$ & 48 & $\begin{array}{l}\text { IV } \\
\text { Glioblastoma IDH } \\
\text { wildtype }\end{array}$ & $\mathrm{R}$ temporal & $\begin{array}{l}\text { S, RTX, } \\
\text { CHT }\end{array}$ & & 11.2 & 40.8 \\
\hline 21 & $M$ & 44 & $\begin{array}{l}\text { IV } \\
\text { Glioblastoma IDH } \\
\text { wildtype }\end{array}$ & $\begin{array}{l}\mathrm{L} \text { fronto- } \\
\text { temporalo- } \\
\text { parietal }\end{array}$ & $\begin{array}{l}\text { S, RTX, } \\
\text { CHT }\end{array}$ & Irinotecan & 19.8 & 51.4 \\
\hline
\end{tabular}

R- right; L- left; S- surgery; RTx- radiotherapy; CHT- chemotherapy, TMZ- Temozolamide 


\begin{tabular}{|c|c|c|c|c|c|c|c|c|}
\hline No & Gender & Age & $\begin{array}{l}\text { Grade and WHO } \\
2016 \text { type }\end{array}$ & $\begin{array}{l}\text { Localisation } \\
\text { [lobe] }\end{array}$ & Treatment & $\begin{array}{l}\text { Other } \\
\text { treatment }\end{array}$ & $\begin{array}{l}\text { Time to } \\
\text { recurrence } \\
\text { [months] }\end{array}$ & $\begin{array}{l}\text { Recurrent } \\
\text { tumor } \\
\text { volume } \\
{\left[\mathrm{cm}^{3}\right]}\end{array}$ \\
\hline 22 & $\mathrm{~F}$ & 54 & $\begin{array}{l}\text { IV } \\
\text { Glioblastoma IDH } \\
\text { wildtype }\end{array}$ & $\begin{array}{l}\text { L parieto- } \\
\text { occipital }\end{array}$ & $\begin{array}{l}\text { S, RTX, } \\
\text { CHT }\end{array}$ & & 5.3 & 22.1 \\
\hline 23 & $M$ & 55 & $\begin{array}{l}\text { IV } \\
\text { Glioblastoma NOS }\end{array}$ & multifocal & $\begin{array}{l}\text { S, RTX, } \\
\text { CHT }\end{array}$ & & 7.5 & 29.1 \\
\hline 24 & $\mathrm{~F}$ & 41 & $\begin{array}{l}\text { IV } \\
\text { Secondary } \\
\text { Glioblastoma IDH } \\
\text { mutant }\end{array}$ & $\begin{array}{l}\mathrm{R} \text { corpus } \\
\text { callosum }\end{array}$ & $\begin{array}{l}\text { S, RTX, } \\
\text { CHT }\end{array}$ & $\mathrm{TMZ}$ & 29.8 & 8.4 \\
\hline 25 & $M$ & 44 & $\begin{array}{l}\text { IV } \\
\text { Secondary } \\
\text { Glioblastoma IDH } \\
\text { mutant }\end{array}$ & $\mathrm{R}$ frontal & S, RTx & $\mathrm{TMZ}$ & 54.3 & 94.9 \\
\hline 26 & $\mathrm{~F}$ & 42 & $\begin{array}{l}\text { IV } \\
\text { Secondary } \\
\text { Glioblastoma IDH } \\
\text { wildtype }\end{array}$ & $\mathrm{R}$ parietal & $\begin{array}{l}\text { S, RTx, } \\
\text { CHT }\end{array}$ & & 119.2 & 40.3 \\
\hline 27 & $M$ & 38 & $\begin{array}{l}\text { IV } \\
\text { Glioblastoma NOS }\end{array}$ & $\begin{array}{l}\text { R parieto- } \\
\text { occipital }\end{array}$ & $\begin{array}{l}\text { S, RTX, } \\
\text { CHT }\end{array}$ & $\mathrm{TMZ}$ & 10.9 & 16.5 \\
\hline 28 & $M$ & 37 & $\begin{array}{l}\text { IV } \\
\text { Glioblastoma IDH } \\
\text { mutant }\end{array}$ & $\mathrm{R}$ parietal & $\begin{array}{l}\text { S, RTX, } \\
\text { CHT }\end{array}$ & $\begin{array}{l}\text { Gene } \\
\text { therapy }\end{array}$ & 32.7 & 56.0 \\
\hline 29 & $M$ & 64 & $\begin{array}{l}\text { IV } \\
\text { Glioblastoma IDH } \\
\text { wildtype }\end{array}$ & multifocal & $\begin{array}{l}\text { S,RTx, } \\
\text { CHT }\end{array}$ & & 2.0 & 41.6 \\
\hline 30 & $\mathrm{~F}$ & 53 & $\begin{array}{l}\text { IV } \\
\text { Glioblastoma IDH } \\
\text { mutant }\end{array}$ & $\begin{array}{l}\text { R parieto- } \\
\text { temporal } \\
\text { multifocal }\end{array}$ & $\begin{array}{l}\text { S, RTX, } \\
\text { CHT }\end{array}$ & $\begin{array}{l}\text { Gamma } \\
\text { knife }\end{array}$ & 44.8 & 38.9 \\
\hline 31 & M & 53 & $\begin{array}{l}\text { IV } \\
\text { Glioblastoma IDH } \\
\text { wildtype }\end{array}$ & multifocal & $\mathrm{S}, \mathrm{CHT}$ & TMZ & 4.0 & 11.4 \\
\hline 32 & $M$ & 50 & $\begin{array}{l}\text { IV } \\
\text { Glioblastoma NOS }\end{array}$ & $L$ frontal & S, RTx & & 6.3 & 52.7 \\
\hline
\end{tabular}

R- right; L- left; S- surgery; RTx- radiotherapy; CHT- chemotherapy, TMZ- Temozolamide 


\begin{tabular}{|c|c|c|c|c|c|c|c|c|}
\hline No & Gender & Age & $\begin{array}{l}\text { Grade and WHO } \\
2016 \text { type }\end{array}$ & $\begin{array}{l}\text { Localisation } \\
\text { [lobe] }\end{array}$ & Treatment & $\begin{array}{l}\text { Other } \\
\text { treatment }\end{array}$ & $\begin{array}{l}\text { Time to } \\
\text { recurrence } \\
\text { [months] }\end{array}$ & $\begin{array}{l}\text { Recurrent } \\
\text { tumor } \\
\text { volume } \\
{\left[\mathrm{cm}^{3}\right]}\end{array}$ \\
\hline 33 & $M$ & 39 & $\begin{array}{l}\text { IV } \\
\text { Glioblastoma IDH } \\
\text { wildtype }\end{array}$ & $\mathrm{R}$ frontal & $\begin{array}{l}\text { S, RTX, } \\
\text { CHT }\end{array}$ & Irinotecan & 13.3 & 77.0 \\
\hline 34 & M & 46 & $\begin{array}{l}\text { IV } \\
\text { Glioblastoma IDH } \\
\text { wildtype }\end{array}$ & $\begin{array}{l}\mathrm{L} \text { fronto- } \\
\text { parietal }\end{array}$ & $\begin{array}{l}\text { S, RTX, } \\
\text { CHT }\end{array}$ & & 10.1 & 200.2 \\
\hline
\end{tabular}

All patients underwent contrast-enhanced MR and $\left[{ }^{68} \mathrm{Ga}\right] \mathrm{Ga}-\mathrm{PSMA}-11 \mathrm{PET} / \mathrm{CT}$ within a 2 weeks' interval.

\section{MR}

MR examinations were performed using GE Excite HD 1.5 T (GE Healthcare, USA) or Siemens 3T MR scanner (Siemens Medical Solutions Inc, USA).

As recommended by Ellingson et al. [17], MR protocol included: T1WI, FLAIR, DWI and after gadolinium-based contrast administration: axial bi-dimensional T2WI and three-dimensional T1WI. The images were viewed and interpreted by two experienced radiologists.

According to the adopted criteria, it was assumed that in patients with high grade gliomas the recurrence was characterized mainly by contrast enhancement in T1WI images and hyperintense lesions in T2WI and FLAIR. In nonenhancing, low grade gliomas recurrence was characterized by hyperintense lesions in T2WI and FLAIR. DWI sequence was used for differentiation between recurrence and pseudoprogression.

\section{[68 Ga]Ga-PSMA-11 PET/CT}

PSMA-11 kit containing $20 \mu \mathrm{g}$ of PSMA-11 (Glu-CO-Lys(Ahx)-HBED-CC) and $60 \mathrm{mg}$ of sodium acetate (POLATOM, Poland) and eluates from a ${ }^{68} \mathrm{Ge} /{ }^{68} \mathrm{Ga}$ Galliapharm generator (Eckert\&Ziegler, Germany) were used for the $\left[{ }^{68} \mathrm{Ga}\right] \mathrm{Ga}$ PSMA-11 preparation. The radiopharmaceutical labeling of $\left[{ }^{68} \mathrm{Ga}\right] \mathrm{Ga}$-PSMA-11 was performed as previously described [18].

The PET/CT image acquisition was performed 60 min post injection of $\left[{ }^{68} \mathrm{Ga}\right] \mathrm{Ga}-\mathrm{PSMA}-11$ (2 MBq per kg body weight) from the skull to the mid-thigh (3-min per bed position, 3 iterations, 21 subsets) on a Biograph 64 TruePoint (Siemens Medical Solutions Inc., USA).

Image analysis was performed using the Siemens Workstation (Syngovia, MMWS, Siemens Medical Solutions Inc, USA). PET/CT scans were analyzed by two certified nuclear medicine physicians with more than 5 years' experience in PET imaging.

On visual evaluation, any cerebral focal uptake higher than the background was interpreted as a positive lesion. For quantitative analysis, the maximal standardized uptake value (SUVmax) and mean standardized uptake value (SUVmean) of each positive lesion were measured using spherical volume of interest. Target-to-background ratios 
(TBR) were calculated using SUVmax of the lesion divided by SUVmax of the background that was measured using a volume of interest of a similar diameter, placed in an unaffected region. Target-to-liver ratios (TLR) were calculated by dividing SUVmax of the lesion by SUVmean of the liver (a similar volume in the center of the right liver lobe). The recurrent tumor volume was measured using the SUVmax threshold of $10 \%$ as previously described [19]. SUVmean was measured in the recurrent tumor volume.

\section{Statistical methods}

In order to summarize the patients' characteristics, means and standard deviations, medians and range depending on the parameters' distribution were used.

Calculations were done on GraphPad PRISM 5 (GraphPad Software Inc) and Excel for MAC (version 16.28, 2019 Microsoft). A non-parametric ANOVA test was used for the statistical comparison between SUVmax, SUVmean, TBR and TLR.

\section{Results}

\section{Toxicity and Safety}

The injection of $\left[{ }^{68} \mathrm{Ga}\right] \mathrm{Ga}-\mathrm{PSMA}-11$ was well tolerated and no adverse events were recorded.

\section{MR findings}

In all patients with recurrence of glioblastoma and anaplastic astrocytoma, focal parenchymal swelling, hyperintense on T2WI and FLAIR with low signal on T1WI were found. Peripheral irregular ring-shaped enhancement around the postoperative cavity or necrosis on post-contrast T1WI were observed. Increase of rCBV in the same regions was visible, as well.

In a patient with multifocal hemangiopericytoma, isointense to grey matter in T1WI, and T2WI/FLAIR signal, as well as vivid enhancement in all foci was noted. In some of them adjacent brain edema was present. Additionally, intermediate restricted diffusion was noted. In this patient, the recurrence of the disease was diagnosed due to the diameter increase of known lesions and visualization of the new one. In patients with oligodendroglioma, the signal intensity was lower in comparison to the grey matter on T1WI images and was hyperintense and heterogenous on T2WI/FLAIR images. No symptoms of peritumoral edema were observed. Contrast enhancement was seen in the case of oligodendroglioma grade III.

\section{$\left[{ }^{68} \mathrm{Ga}\right]$ Ga-PSMA-11 PET/CT image analysis}

Physiological uptake in lacrimal and salivary glands, tonsils, liver, spleen, kidneys and duodenum was observed in all the patients. The background normal brain tissue showed extremely low uptake in all cases, with SUVmax $<0.23$ in all and $<0.1$ in the majority of images.

In all the lesions detected at MR, an increased accumulation of $\left[{ }^{68} \mathrm{Ga}\right] \mathrm{Ga}-\mathrm{PSMA}-11$ was found, though with different intensity. In 7 patients, multiple foci of increased [ $\left.{ }^{68} \mathrm{Ga}\right] \mathrm{Ga}-\mathrm{PSMA}-11$ accumulation were visualized: 2 lesions in 3 patients, 3 lesions in 2, and 4 lesions in 2 patients. In these subjects, a lesion with the highest uptake was selected for the per-patient analysis. Median SUVmax in the entire group was 6.5 (range: 0.9-15.6) and SUVmean was 3.5 (range: $0.9-7.5$ ). TBR varied between 15 and 1400 with a median of 152 . TLR ranged from 0.2 to 2.6 , the median TLR was 1.3. 
These values were assessed separately in subgroups according to the glioma grade III-IV (see Table 2). No statistically significant difference was found between the subgroups in any of the analyzed parameters.

Table 2

Analyzed parameters: SUVmax, SUVmean, TBR and TLR in the subgroups - per-patient analysis

\begin{tabular}{|lllll|}
\hline Grade & III & \multicolumn{3}{l|}{ IV } \\
\hline Number of pts. & 6 & & 28 & \\
\hline & range & median & range & median \\
\hline SUVmax & $2.1-11.2$ & 6.2 & $1.3-15.6$ & 7.1 \\
\hline SUVmean & $2.1-5.5$ & 3.3 & $1.3-7.5$ & 3.5 \\
\hline TBR & $21-186$ & 72 & $18-1400$ & 89 \\
\hline TLR & $0.3-2.6$ & 0.8 & $0.7-2.8$ & 1.1 \\
\hline
\end{tabular}

Subsequently, per-lesion analysis was performed in which 47 foci found in 34 patients (27 pts. with unifocal and 7 with multifocal recurrence) were inspected separately (Table 3). No significant difference between the groups in any parameter was found either.

Table 3

Analysed parameters: SUVmax, SUVmean, TBR and TLR in the subgroups - per-lesion analysis

\begin{tabular}{|lllll|}
\hline Grade & III & \multicolumn{3}{l|}{ IV } \\
\hline No. of lesions & 11 & & 36 & \\
\hline SUVmax & $0.9-11.2$ & 5.6 & $1.3-15.6$ & 6.6 \\
\hline SUVmean & $0.9-5.5$ & 3.3 & $1.3-7.5$ & 3.5 \\
\hline TBR & $15-186$ & 70 & $18-1400$ & 82 \\
\hline TLR & $0.2-2.6$ & 0.8 & $0.4-2.8$ & 1.2 \\
\hline
\end{tabular}

Brain images in different grades of glial tumors are shown in Figs. 1-3.

\section{Correlation between MR and $\left[{ }^{68} \mathrm{Ga}\right] \mathrm{Ga}-\mathrm{PSMA}-11$ PET/CT image}

All areas with contrast enhancement on MR were associated with increased $\left[{ }^{68} \mathrm{Ga}\right] \mathrm{Ga}-\mathrm{PSMA}-11$ accumulation. Subsequently, $\left.{ }^{68} \mathrm{Ga}\right] \mathrm{Ga}-\mathrm{PSMA}-11 \mathrm{PET}$ and MR images were fused using the semiautomatic software with manual adjustment for correct alignment. Visual interpretation showed increased accumulation of $\left[{ }^{68} \mathrm{Ga}\right] \mathrm{Ga}-\mathrm{PSMA}-11$ precisely in the contrast-enhanced portions of the tumor at MR. The part of the tumor that was interpreted as necrotic in MR did not show any accumulation of [ $\left.{ }^{68} \mathrm{Ga}\right] \mathrm{Ga}-\mathrm{PSMA}-11$.

\section{Confirmation of recurrence}


Following the PET/CT, the diagnosis of recurrence was confirmed in all patients: by means of histopathology in 16 patients (1-14 days after PET/CT) and by means of follow-up imaging that documented further progression (subsequent MR or another $\left[{ }^{68} \mathrm{Ga}\right] \mathrm{Ga}$-PSMA-11 PET/CT performed 2-6 weeks after PET/CT) in the remaining 18 subjects.

The localization for histopathological sampling was selected in the area of the highest $\left[{ }^{68} \mathrm{Ga}\right] \mathrm{Ga}-\mathrm{PSMA}-11 \mathrm{uptake}$. We did not record any false-positive scans in comparison to histopathology.

\section{Discussion}

Routinely, the diagnosis of glial tumors recurrence is made on the basis of MR examinations, including T1WI (without and with contrast injection), T2WI and FLAIR sequences. As these techniques do not measure specifically the tumor activity, more advanced imaging techniques have been employed: DWI, DCE or MRS. The recent metaanalysis of van Dijken et al. [20] showed that pooled sensitivity and specificity of anatomical MR in the evaluation of treatment response amounted to $68 \%$ and $77 \%$, respectively. Pooled apparent diffusion coefficients demonstrated a sensitivity of $71 \%$ and specificity of $87 \%$. DSC perfusion sensitivity was $87 \%$ with a specificity of $86 \%$ and DCE perfusion sensitivity was $92 \%$ and specificity was $85 \%$.

PSMA is a transmembrane glycoprotein expressed in the endothelial cells of neovasculature of various tumors (breast and renal carcinoma) [21, 22]. Based on immunohistochemical examinations, Wernicke et al. reported the PSMA expression in all 32 grade IV glioma tumors, specifically in their vasculature [7]. Other authors confirmed a positive result of the PSMA staining in high-grade glioma specimens $[8,23]$. In contrast, the PSMA expression was relatively infrequent in low-grade gliomas $[11,24]$.

These in-vitro results laid the foundation for the new imaging option of glial tumors with radiolabeled PSMA ligands with the use of PET/CT technology. The first case report of $\left[{ }^{68} \mathrm{Ga}\right] \mathrm{Ga}-\mathrm{PSMA}-11$ accumulation in glioblastoma multiforme was published in 2015 [25]. Later studies showed very promising results on some larger patient series (from 3 to 15 cases) that concordantly reported positive $\left[{ }^{68} \mathrm{Ga}\right] \mathrm{Ga}-\mathrm{PSMA}-11$ PET/CT scans in all the examined glioblastoma multiforme cases [10-12, 14, 17]. In the present preliminary study, the cohort of 34 patients with glial tumors is analyzed. As many as 28 of them had the diagnosis of grade IV glioma, and the results in this subgroup, similarly to the papers mentioned above, demonstrate high tracer uptake in the recurrent tumor. The areas of recurrence presented as foci of intense tracer accumulation with a median SUVmax of 7.1 (the highest SUVmax value in one of the patients was 15.6 - Fig. 3). On the other end of the uptake range, there were some patients with glioblastoma multiforme, with relatively low SUVmax (1.3 was the lowest value recorded in this subgroup). However, even these foci of recurrence could be easily delineated at the PET/CT scans because of generally extremely low $\left[{ }^{68} \mathrm{Ga}\right] \mathrm{Ga}-\mathrm{PSMA}-11$ uptake in the normal brain parenchyma. The median SUVmax of the normal brain was as low as 0.1. Adequately, the contrast between the malignant infiltration and the background was very good in all the grade IV cases. The subsequently high TBR values (median 89.6) are concordant with the in-vitro findings of absent PSMA expression in the normal brain vasculature $[7,8]$. Due to the remarkable TBR, $\left[{ }^{68} \mathrm{Ga}\right] \mathrm{Ga}-\mathrm{PSMA}-11 \mathrm{PET} / \mathrm{CT}$ offers an advantage over other tracers. For example, a median TBR of 3.8 was reported recently for $\left[{ }^{11} \mathrm{C}\right]$ methionine PET/MR in newly diagnosed glioblastoma [26] and median TBR of 3.2 was obtained in [ $\left.{ }^{18} \mathrm{~F}\right]$ fluoroethyltyrosine PET/MR in a group of 32 patients with high-grade glioma recurrence [27].

Interestingly, we did not record any false-positive scans. A single case of an increased PSMA ligand accumulation in radionecrosis has been published till now [28]. This finding may represent a potential limitation to the application of 
PSMA-targeted agents, but it is not supported by our data.

The representation of cases with glial tumors of other grades than IV seems to be an additional value of our study. Despite the fact that the subgroup of grade III contains only 6 cases, it can still be considered the largest collective reported so far. Considering that three of these patients had a multifocal recurrence, the per-lesion analysis of 11 tumors in total could be performed. Moreover, the uptake parameters in multiple tumors of the same patient were not always similar. For example, in the patient with four foci of oligodendroglioma relapse (patient No.4), the SUVmax ranged from 0.9 to 11.2. This anecdotal observation provides another evidence of biological heterogeneity of multifocal tumors. In general, performance of $\left[{ }^{68} \mathrm{Ga}\right] \mathrm{Ga}$-PSMA-11 PET/CT in grade III was as excellent as in grade IV. Similarly, high uptake parameters were measured in this subgroup. Some positive experiences with the PSMA imaging in grade III gliomas were also shared by Sasikumar et al., whose 2 patients with anaplastic oligodendroglioma and anaplastic astrocytoma presented with TBR of 11.9 and 27.0 [12].

Comparison of PET and MR scans showed that the accumulation of [ $\left.{ }^{68} \mathrm{Ga}\right] \mathrm{Ga}-\mathrm{PSMA}-11$ was found precisely in the tumor regions that showed contrast enhancement. Gadolinium-based contrast agents shorten T1 relaxation times and increase tissue contrast by accentuating areas where contrast agents have leaked into the interstitial tissues crossing the blood-brain barrier. The breakdown of the barrier and neoangiogenesis are key features seen not only in primary tumors but also in the recurrences. A better indicator of angiogenesis is the increase in rCBV. In the group of 15 patients for whom this study was available, a clear correlation was found between the accumulation of $\left[{ }^{68} \mathrm{Ga}\right] \mathrm{Ga}-$ PSMA-11 and rCBV. On the other hand, the region of T2WI/FLAIR hyperintense signal abnormality surrounding the enhancing part of a tumor or its recurrence is typically referred to as peritumoral edema and can be of vasogenic or infiltrative nature. The infiltrative edema in gliomas represents a mixture of vasogenic edema and infiltrating tumor cells and can be considered as a non-enhancing tumor without pathological angiogenesis and with preserved integrity of the blood-brain barrier. In fact, in many gliomas, the T2WI/FLAIR hyperintense signal abnormality may be indistinguishable from the primary mass lesion. It seems that the processes responsible for both, the imaging patterns in MR and the uptake of $\left[{ }^{68} \mathrm{Ga}\right] \mathrm{Ga}-\mathrm{PSMA}-11$, are similar and this explains the obtained results.

The discovery of PSMA expression in glial tumors has provided rationale for this particular imaging modality but it can also be considered in the context of the targeted radionuclide therapy with $\beta$ or a-emitters. First experimental therapy of glioblastoma multiforme using $\left[{ }^{177}\right.$ Lu]Lu-PSMA-617 applied intravenously has been recently published by our group [29]. Despite earlier concern about a quick washout of the compound due to the non-specific uptake in microvascular endothelium (instead of the tumor cells), we were able to demonstrate a long-lasting accumulation of the $\beta$-emitting radioligand within the tumor. This finding seems to predict good chances for the development of this kind of treatment. For the qualification to PSMA-based radionuclide targeted therapy the TLR of more than 1.5 is commonly used as a qualification criterion to the radionuclide therapy [30]. If the [ ${ }^{68} \mathrm{Ga}$ ]Ga-PSMA-11 PET/CT had been used for qualification to the radionuclide therapy in this group, the criterion of TLR $>1.5$ would have been fulfilled by one third of the patients.

There are some limitations to this study. First, the sample size in grade III is small, so the differences in the measured parameters between grade III and grade IV subgroups, if any, do not reach statistical significance. Therefore, more extensive research on a larger number of patients, possibly multicenter trials, are warranted. The relatively small number of cases included is the result of strict inclusion criteria: only patients with a suspicion of recurrence were qualified. PET/CT scans obtained at different clinical settings, i.e. for staging or treatment response were not included. This rule should be appreciated as an advantage of this paper. But on the other hand, it could be considered as weakness, since only true-positive scans were acquired. Presence of patients without recurrence, with 
false-positive findings or with a negative scan despite relapse, would allow us to calculate the sensitivity and specificity.

\section{Conclusion}

This study shows excellent results of $\left[{ }^{68} \mathrm{Ga}\right] \mathrm{Ga}$-PSMA-11 PET/CT in the diagnosis of glioma recurrence of III-IV grades. Due to the low background activity, this method provides high-quality images and allows for the detection of well-defined recurrent lesions. As the treatment options in recurrent glioma are limited, demonstration of in-vivo PSMA expression in the recurrent tumor opens new perspectives for the development of PSMA-based radionuclide treatment modalities.

\section{Abbreviations}

PSMA = Prostate specific membrane antigen

SUVmax = maximal standardized uptake value

SUVmean = mean standardized uptake value

TBR $=$ target-to-background ratio

TLR = target-to-liver ratio

\section{References}

1. Louis, D. N., Ohgaki, H., Wiestler, O. D. \& Cavenee, W. K. World Health Organization histological classification of tumours of the central nervous system. Revised. Fourth Edition (International Agency for Research on Cancer, France, 2016).

2. Choi, C. et al. 2-hydroxyglutarate detection by magnetic resonance spectroscopy in IDH-mutated patients with gliomas. Nat Med, 18, 624-629 (2012).

3. Wen, P. Y. et al. Updated response assessment criteria for high-grade gliomas: response assessment in neurooncology working group. J Clin Oncol, 28, 1963-1972 (2010).

4. Jiang, S. et al. Identifying recurrent malignant glioma after treatment using amide proton transfer-weighted MR imaging: a validation study with image-guided stereotactic biopsy. Clin Cancer Res, 25, 552-561 (2019).

5. Kim, Y. H. et al. Differentiating radiation necrosis from tumor recurrence in high-grade gliomas: assessing the efficacy of 18F-FDG PET, 11C-methionine PET and perfusion MR. Clin Neurol Neurosurg, 112, 758-765 (2010).

6. Evangelista, L. et al. Comparison between 18F-DOPA and 18F-FET PET/CT in patients with suspicious recurrent high grade glioma: a literature review and our experience. Current Radiopharm, 12, 220-228 (2019).

7. Wernicke, A. G. et al. Prostate-specific membrane antigen as a potential novel vascular target for treatment of glioblastoma multiforme. Arch Pathol Lab Med, 135, 1486-1489 (2011).

8. Nomura, N. et al. Prostate specific membrane antigen (PSMA) expression in primary gliomas and breast cancer brain metastases. Cancer Cell Int, 14, 26 (2014).

9. Eiber, M. et al. Evaluation of hybrid 6Ga-PSMA ligand PET/CT in 248 patients with biochemical recurrence after radical prostatectomy. J Nucl Med, 56, 668-674 (2015). 
10. Sasikumar, A. et al. Diagnostic value of 68Ga PSMA-11 PET/CT imaging of brain tumors - preliminary analysis. Clin Nucl Med, 42, e41-e48 (2017).

11. Matsuda, M. et al. Potential use of prostate specific membrane antigen (PSMA) for detecting the tumor neovasculature of brain tumors by PET imaging with 89Zr-Df-IAB2M anti-PSMA minibody. J Neurooncol, 138, 581-589 (2018).

12. Sasikumar, A. et al. Utility of $68 \mathrm{Ga}-\mathrm{PSMA}-11$ PET/CT in imaging of glioma - a pilot study. Clin Nucl Med, 43 , e304-e309 (2018).

13. Marafi, F., Sasikumar, A. \& Fathallah, W. Esmail A.18F-PSMA 1007 brain PET/CT imaging in glioma recurrence. Clin Nucl Med, 45, e61-e62 (2020).

14. Verma, P. et al. Differential uptake of 68Ga-PSMA-HBED-CC (PSMA-11) in low-grade versus high-grade gliomas in treatment-naive Patients. Clin Nucl Med, 44, e318-e322 (2019).

15. Salas Fragomeni, R. A. et al. Prostate-specific membrane antigen-targeted imaging with [18F]DCFPyL in highgrade gliomas. Clin Nucl Med, 42, e433-e435 (2017).

16. Kunikowska, J., Królicki, B. \& Królicki, L. Glioblastoma multiforme: another potential application for 68Ga-PSMA PET/CT as a guide for targeted therapy. Eur J Nucl Med Mol Imaging.2018;45:886-887.

17. Ellingson, B. M. et al. Consensus recommendations for a standarized brain tumor imaging protocol in clinical trials. Neuro-oncology, 17, 1188-1198 (2015).

18. Kunikowska, J., Kuliński, R., Muylle, K., Koziara, H. \& Królicki, L. 68Ga-Prostate-Specific Membrane Antigen-11 PET/CT: a new imaging option for recurrent glioblastoma multiforme? Clin Nucl Med, 45, 11-18 (2020).

19. Królicki, L. et al. Safety and efficacy of targeted alpha therapy with 213Bi-DOTA-substance $P$ in recurrent glioblastoma. Eur J Nucl Med Mol Imaging, 46, 614-622 (2019).

20. van Dijken, B. R. J., van Laar, P. J., Holtman, G. A. \& van der Hoorn, A. Diagnostic accuracy of magnetic resonance imaging techniques for treatment response evaluation in patients with high-grade glioma, a systematic review and meta-analysis. Eur Radiol, 27, 4129-4144 (2017).

21. Carter, R. E., Feldman, A. R. \& Coyle, J. T. Prostate-specific membrane antigen is a hydrolase with substrate and pharmacologic characteristics of a neuropeptidase. Proc Natl Acad Sci USA, 93, 749-753 (1996).

22. Chang, S. S. et al. Five different anti-prostate-specific membrane antigen (PSMA) antibodies confirm PSMA expression in tumor-associated neovasculature. Cancer Res, 59, 3192-3198 (1999).

23. Mahzouni, P. \& Shavakhi, M. Prostate-specific membrane antigen expression in neovasculature of glioblastoma multiforme. Adv Biomed Res, 8, 18 (2019).

24. Saffar, H., Noohi, M., Tavangar, S. H., Saffar, H. \& Azimi Expression of prostate-specific membrane antigen (PSMA) in brain glioma and its correlation with tumor grade. Iran J Pathol, 13, 45-53 (2018).

25. Schwenck, J. et al. In vivo visualization of prostate-specific membrane antigen in glioblastoma. Eur J Nucl Med Mol Imaging, 42, 170-171 (2015).

26. Kebir, S., Weber, M. \& Lazaridis, L. Hybrid 11C-MET PET/MR combined with "machine learning" in glioma diagnosis according to the revised glioma WHO classification 2016. Clin Nucl Med, 44, 214-220 (2019).

27. Lohmeier, J. et al. Quantitative biparametric analysis of hybrid ${ }^{18}$ F-FET PET/MR-neuroimaging for differentiation between treatment response and recurrent glioma. Sci Rep. 2019; 2019; 9: 14603.

28. Salas Fragomeni, R. A., Pienta, K. J., Pomper, M. G., Gorin, M. A. \& Rowe, S. P. Uptake of prostate-specific membrane antigen-targeted 18F-DCFPyL in cerebral radionecrosis: implications for diagnostic imaging of highgrade gliomas. Clin Nucl Med, 43, e419-e421 (2018). 
29. Kunikowska, J. et al. Tumor uptake in glioblastoma multiforme after IV injection of [177Lu]Lu-PSMA-617. Eur J Nucl Med Mol Imaging, 47, 1605-1606 (2020).

30. Kratochwil, C. et al. EANM procedure guidelines for radionuclide therapy with 177Lu-labelled PSMA-ligands (177Lu-PSMA-RLT). Eur J Nucl Med Mol Imaging, 46, 2536-2544 (2019).

\section{Figures}
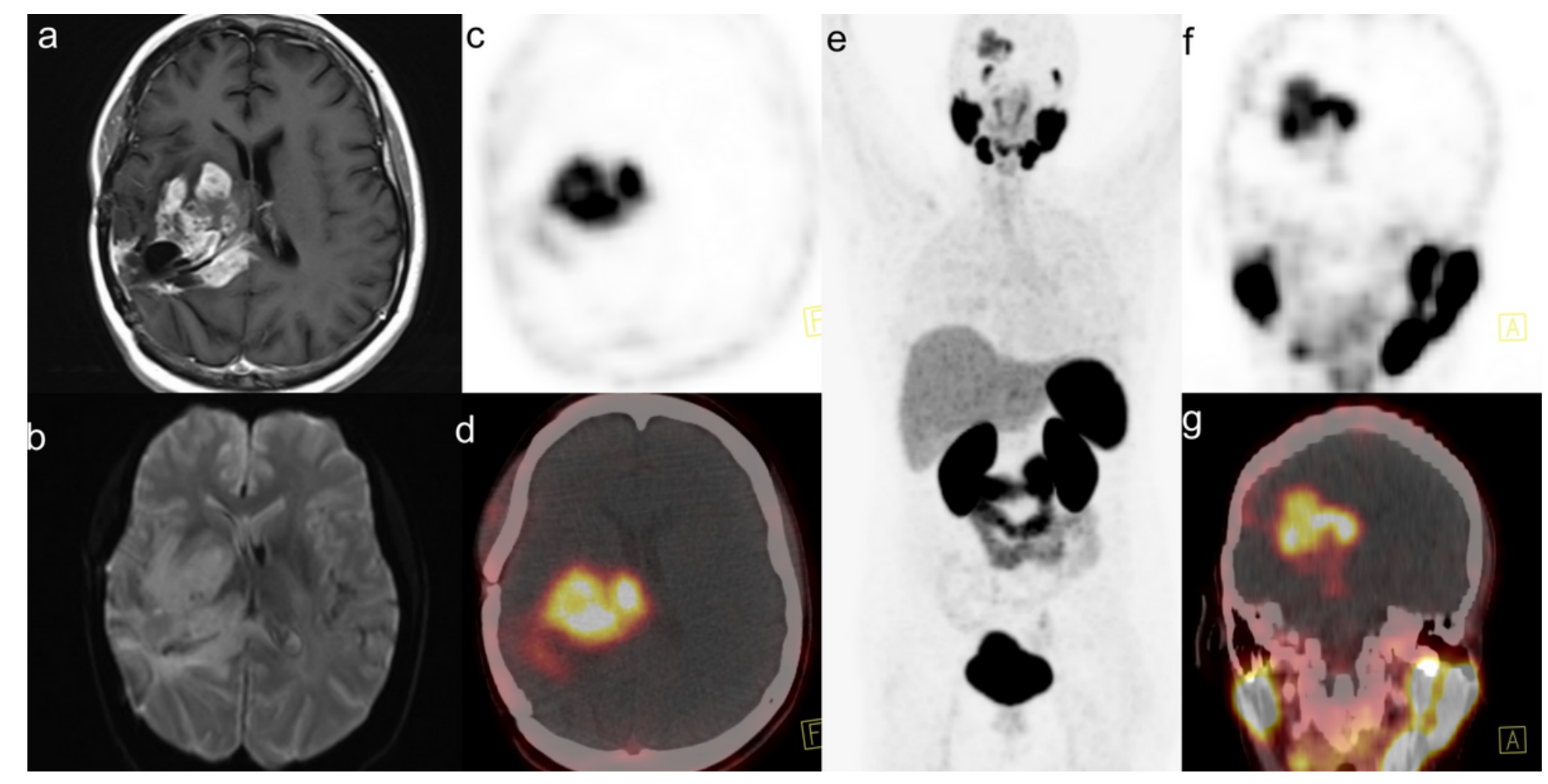

\section{Figure 1}

Male, 39 yrs., with a recurrent anaplastic astrocytoma IDH wildtype grade III in the right parieto-occipital frontal lobe. Three years after surgery, and 15 months after local radionuclide therapy with [213Bi]Bi-DOTA-SP, a contrastenhanced mass around the surgical cavity was detected with MR. [68Ga]Ga-PSMA-11 accumulation in the tumor was found with the SUVmax 4.9, SUVmean 3.3, TBR 70 and TLR 0.8; (a - contrast-enhanced T1WI, B- DWI, c- PET transverse image, $d$ - fused PET/CT transverse image, $e$ - maximal intensity projection, $f$ - PET sagittal image, gfused PET/CT sagittal image) 


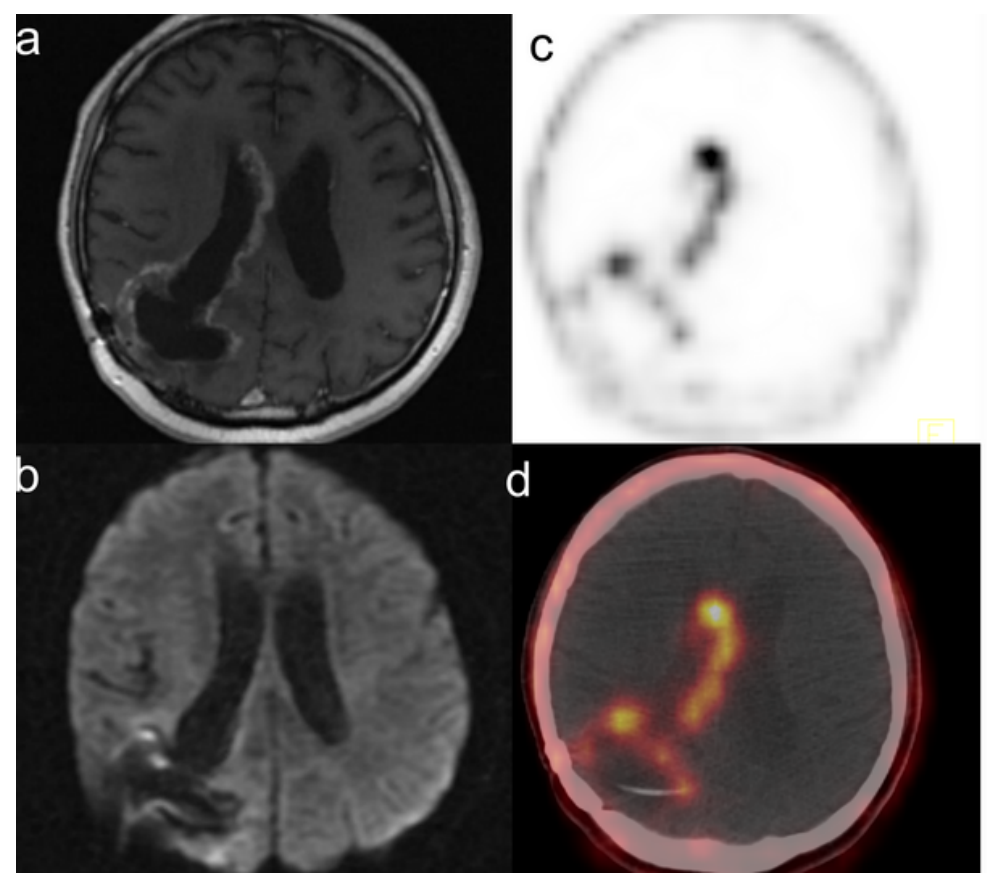

e

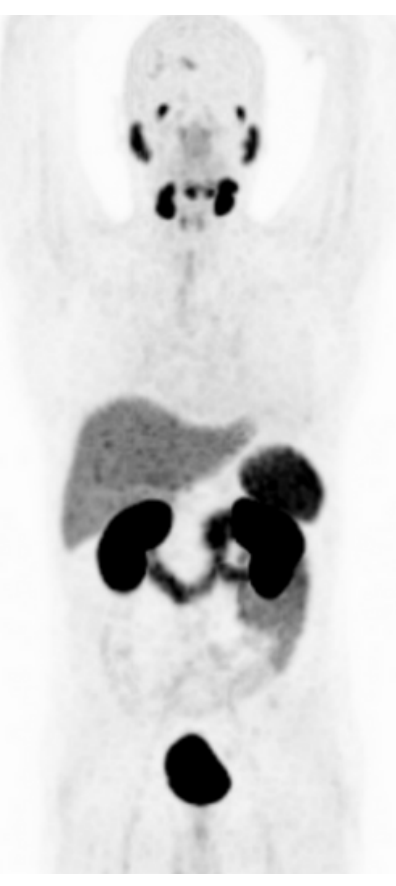

f

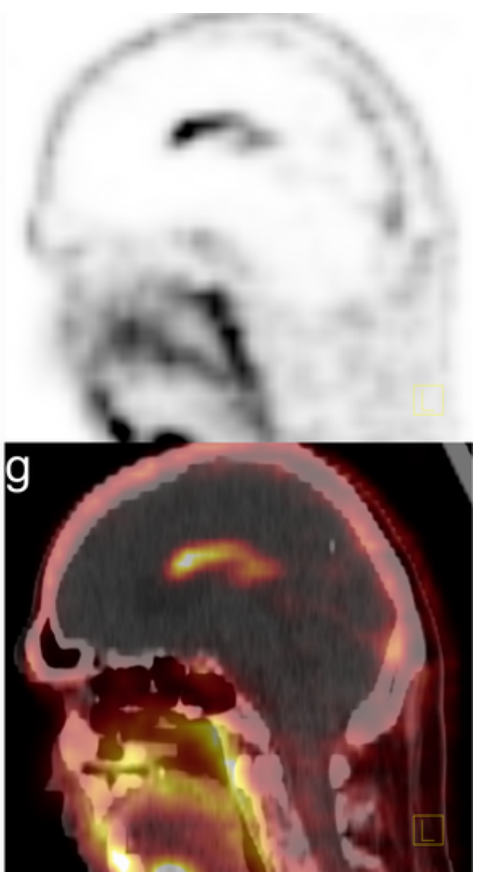

\section{Figure 2}

Female, 42 yrs., with a recurrent secondary glioblastoma in the right parietal lobe. Initially, she was diagnosed with glioma tumor grade II and underwent surgery. A follow-up MR revealed a contrast-enhanced mass around the surgical cavity 119.2 months after primary treatment. PET/CT showed high [68Ga]Ga-PSMA-11 accumulation in the tumor; with the SUVmax 17.4, SUVmean 7.4, TBR 870 and TLR 3.4 (a - contrast-enhanced T1WI, B- DWI, c- PET transverse image, $d$ - fused PET/CT transverse image, $e$ - maximal intensity projection, $f$ - PET sagittal image, $g$ fused PET/CT sagittal image) 


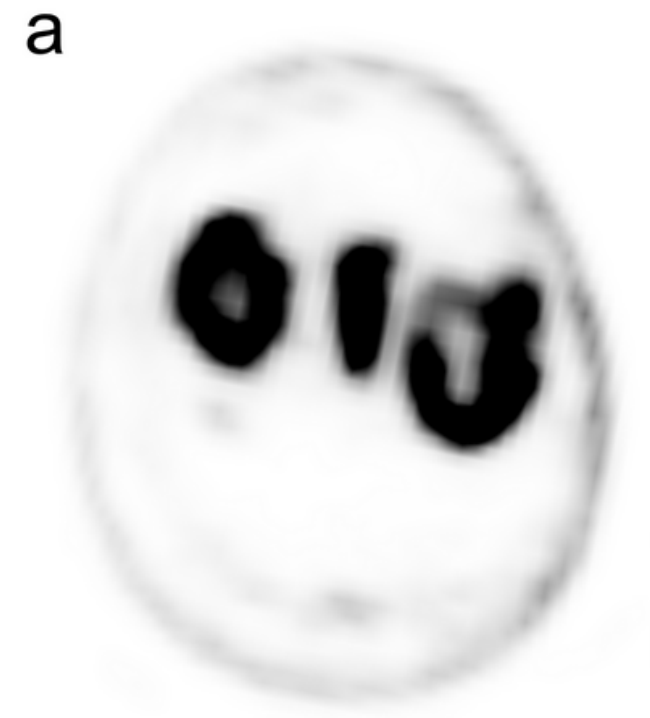

C
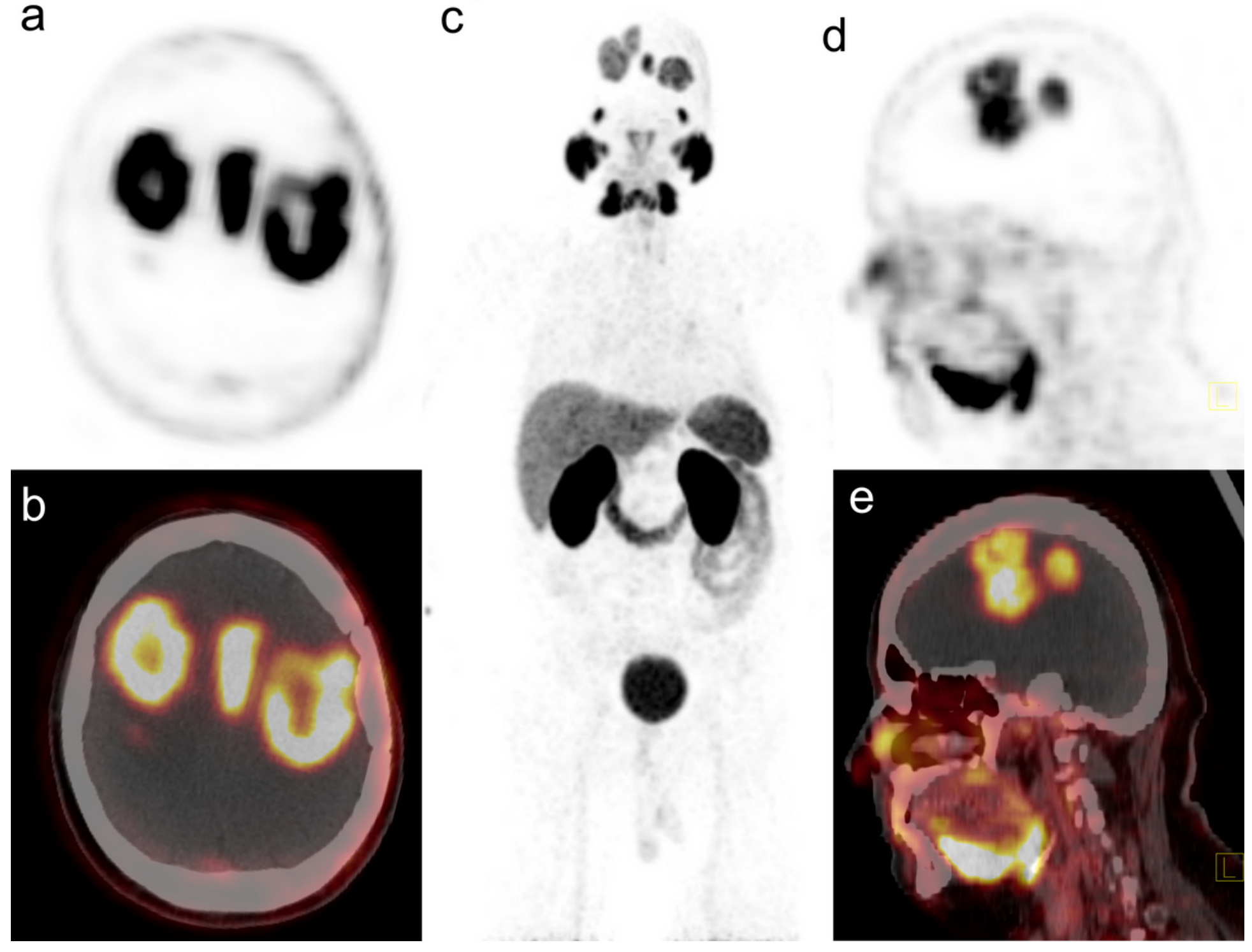

Figure 3

Male, 54 yrs., with a recurrent multiple high-grade glioma. MR performed 4 months after treatment initiation revealed a mass around the surgical cavity in the left temporo-parietal lobe and multifocal tumors in the right frontal, right parietal lobe and parasagittal area. [68Ga]Ga-PSMA-11 PET/CT showed high accumulation in the all tumors with the highest SUVmax 15.6, SUVmean 7.5, TBR 156 and TLR 2.8 ( $a$ - PET transverse image, $b$ - fused PET/CT transverse image, $c$ - maximal intensity projection, $d$ - PET sagittal image, e - fused PET/CT sagittal image) 